\title{
Elementos para una historia de las violencias estatales en la Argentina en el siglo XX
}

\author{
(4) Ernesto Bohoslavsky \\ Programa de Historia Contemporánea de la Universidad Nacional de General Sarmiento/ \\ CONICET, Argentina. \\ ebohosla@campus.ungs.edu.ar

\section{Marina Franco} \\ Instituto de Altos Estudios Sociales de la Universidad Nacional de San Martín/CONICET, \\ Argentina. \\ mfranco@unsam.edu.ar
}

Artículo recibido: 03 de junio de 2019. Aprobación final: 12 de diciembre de 2019.

\begin{abstract}
Resumen
Este artículo revisa algunos supuestos historiográficos en torno al estudio de las formas de represión estatal en Argentina en el siglo XX y ofrece una serie de sugerencias metodológicas y conceptuales sobre el tema. En primer lugar se señala la necesidad de morigerar el uso recurrente de la escala nacional con el fin de percibir las particularidades regionales y globales de muchas prácticas represivas. En segundo lugar, se sugiere poner en cuestión la separación historiográfica entre quienes estudian la historia argentina antes y después de 1955 para detectar fenómenos de continuidad y de larga duración en el siglo XX. La tercera sección discute el peso excesivo que la historiografía suele otorgarle a la "cuestión peronista" lo cual ha condicionado la comprensión de la dinámica de violencia y represión política en la segunda parte del siglo. En el final de este texto se presentan algunas reflexiones para avanzar en caminos alternativos hacia una comprensión más ajustada de las formas de la violencia política estatal en Argentina.
\end{abstract}




\title{
Elements for a State Violence History of Argentina in the 20th Century
}

\begin{abstract}
This paper discusses some historiographical themes on the history of State repression in Argentina during the 20th Century and simultaneously proposes some methodological and conceptual suggestions for this field. Firstly, the authors suggest the need to move away from a frequently national focus and scale, in order to perceive some regional and global features of many repressive practices. Secondly, they lay out a debate concerning the historiographical split between the historians who study Argentine history before 1955 and those who study it after 1955. In doing so, the paper detects continuities and long-term phenomena along the 20th century. The third section discusses the excessive weight that historians give to the "cuestión peronista" and argues that such an approach limits the understanding of the violence and political repression dynamics in the second half of the century. The final section of the paper offers some proposals to pave the way to an alternative interpretation of the features of the State political repression in Argentina.
\end{abstract}

Keywords: Violence, Argentina, 20th Century, Political History.

\section{Introducción ${ }^{1}$}

En este texto proponemos una discusión eminentemente historiográfica sobre las formas, dispositivos, usos y procesos de legitimación de las violencias represivas desplegadas por agencias y actores estatales en la Argentina a lo largo del siglo XX. El objetivo de esta reflexión es sumarse al proceso en marcha de constitución un campo específico de estudios sobre la violencia estatal, en este caso con la ambición particular de pensar el tema de manera integrada, comprensiva y con perspectiva de largo plazo para todo el siglo. Ello supone establecer diálogos con ámbitos de investigación cercanos, constituidos con otros criterios de indagación, otros problemas y/o abocados a períodos distintos que suelen tener poco vínculo entre sí.

En forma provisoria, aquí consideraremos al siglo XX argentino como el que se inicia en 1902 -año de la aprobación de la Ley de Residencia- y se cierra en 2001, año de la última declaración de estado de sitio. Una primera definición operativa del objeto es imprescindible para delimitar conceptualmente la vastedad del problema. Entendemos las violencias represivas estatales como el conjunto de

1 Una primera versión de este texto fue presentada en el "III Coloquio Internacional sobre Violencia Política en el Siglo XX" y en una reunión del Programa de Historia Contemporánea de la Universidad Nacional de General Sarmiento. Agradecemos a quienes participaron de esos eventos por sus sugerencias y críticas, lo mismo que a Luciano Alonso, Lila Caimari, Alejandro Cattaruzza y Daniel Lvovich por sus lecturas de versiones anteriores de este artículo. 
mecanismos y recursos desplegados por instituciones estatales dotadas de autoridad legítima o de facto y dirigidos al control y la sanción a través del empleo de la coerción -o la amenaza de usarla- contra individuos o grupos a los que se considera desafiantes de las relaciones de poder existentes (a partir de González Calleja, 2006). No obstante, cualquier estudio sobre el Estado no puede desatender la presencia de acciones represivas desplegadas por actores y organizaciones formalmente no ligados al Estado pero sí vinculados y financiados por él, como son los grupos para-militares o para-policiales. ${ }^{2}$ Aun considerando las diferencias entre ambas, esta delimitación debiera considerar tanto las estrategias reactivas (detención, encierro, persecución judicial, elaboración de listas negras, represión, exilio y formas extremas de violencia física que pueden incluir el homicidio) como las preventivas (inteligencia, vigilancia y legislación restrictiva de movimiento y de expresión, legislación de excepción). En contraste, se excluyen las formas regulares de organización del Estado tendientes a obtener el ordenamiento y el encuadramiento social a través de instituciones como la escuela o el servicio militar obligatorio, o la policía cuando realiza tareas ordinarias de persecución de los crímenes contra la propiedad o el honor.

Las violencias estatales de tipo represivas han sido un rasgo permanente de la historia argentina ya desde la constitución del Estado-Nación moderno a mediados del siglo XIX, incluyendo las campañas militares contra las sociedades indígenas patagónicas, bonaerenses y del noroeste del territorio a finales de esa centuria. A pesar de ello, la perspectiva historiográfica sobre el tema ha quedado fuertemente centrada en la segunda parte del siglo XX y, muy en particular, sobre el terrorismo de Estado y la desaparición forzada de personas en los años setenta. ${ }^{3}$ Probablemente, lo extremo de ese proceso y las violencias políticas que se descargaron sobre múltiples capas sociales que incluían a integrantes de las elites sociales y políticas (Halperin Donghi, 1987) engulleron buena parte de nuestras posibilidades de percibir otras cuestiones y de pensar más articuladamente las violencias estatales de toda la centuria, en particular las posteriores a $1983 .{ }^{4}$ La concentración de la discusión sobre las violencias de Estado en los años setenta del siglo XX ha priorizado el estudio de ciertas variables, en particular, los mecanismos clandestinos, la prisión política y la intensificación de la coerción de las Fuerzas Armadas para responder a los conflictos políticos de esa época (la "cuestión peronista", la radicalización política

2 Desde luego se trata de fenómenos diferentes que requieren herramientas distintas de estudio y que para ciertos períodos han sido estudiadas por campos académicos distintos; sin embargo, es necesario considerarlos como parte de un mismo problema global si de lo que se trata es de pensar ampliamente el funcionamiento represivo del Estado, los diversos grupos que lo habitan y utilizan sus mecanismos coercitivos legales y clandestinos.

3 Al punto de que hoy existen líneas de trabajo muy sólidas sobre el tema, que están en la base del desarrollo del campo de la historia reciente a la fecha (Franco y Lvovich, 2017). Véase la fuerte presencia de los trabajos sobre represión en el campo de la historia reciente, en particular, la Red de estudios sobre represión y violencia política (RER) (https://redestudiosrepresion.wordpress.com/). De hecho, la RER concentra su interés, temporalmente, en la última dictadura y los períodos cercanos a ese proceso. De igual manera, no existen campos temáticos de similar envergadura para la primera parte del siglo XX. Para una presentación de los estudios sobre represión en la historia reciente, véase Águila, 2018.

4 Existen muy pocos estudios académicos que toman períodos extensos del siglo XX y suelen referirse a actores específicos como las Fuerzas Armadas (Potash, 1969, 1980 y 1994 y Rouquié, 1978), las derechas civiles (Finchelstein, 2002), la policía (Andersen, 2002) o el estado de sitio y la legislación de emergencia (Negretto, 1995; Ziulu, 2000). También hay algunas narraciones más amplias de carácter descriptivo o ilustrativo sobre la violencia, que no permiten construir un verdadero problema histórico (Larraquy, 2017; Rodríguez Molas, 1984; Bayer 2006). 
de las izquierdas, los "azos" iniciados en 1969, etc.). Ello ha dejado poco interés en otros procesos represivos previos, similares o no, pero conectables analíticamente, al punto de que las violencias estatales represivas de la primera parte del siglo suelen ser objeto privilegiado de especialistas de la historia del movimiento obrero, del anarquismo o de agencias estatales como la policía. ${ }^{5}$

Pensar la violencia represiva en la Argentina no supone que ésta haya sido un rasgo exclusivo de nuestro país o que aquí presente características más extremas que en otras sociedades: todas las teorías críticas desde el siglo XIX han mostrado con creces que el despliegue de estrategias de control social y político forma parte del Estado como sistema de dominación. Por el contrario, aquí nos preguntamos por las características específicas del caso argentino, por sus variaciones a lo largo del tiempo y por aquellas características compartidas con otros países latinoamericanos. ${ }^{6}$ Atender al caso argentino no supone tampoco la denuncia de sus males como un flujo permanente e indiferenciado de represión, sino interrogarse por las maneras situadas de gestión del conflicto político-social por parte de un Estado que funcionó bajo diversas configuraciones de poder y respondió de formas distintas a esa conflictividad a lo largo del siglo, aun cuando se puedan reconocer elementos de continuidad en las maneras en que las agencias del Estado configuraron sus respuestas a las amenazas. En cualquier caso, en esta primera indagación pretendemos discutir algunos obstáculos que plantean las periodizaciones habituales, tales como la mirada que divide el siglo XX como escindido entre regímenes democráticos y dictaduras.

Frente a este panorama -descripto de manera inevitablemente esquemática-, en este texto proponemos algunas preguntas sobre las matrices historiográficas que subyacen en el estudio de la violencia estatal -y a veces no sólo sobre ella-,y sugerimos algunas consideraciones sobre el problema. Pondremos el acento en tres cuestiones que se discuten en cada una de las secciones que componen este trabajo:

a) Escalas. Sostenemos la conveniencia de avanzar más en descentrar el uso de la escala nacional (o considerada como tal) y articularla mejor con las escalas local, regional e internacional para abordar la historia de las violencias represivas en la Argentina. Descentrar la escala nacional quiere decir, paradójicamente, alejar la vista del ombligo argentino (o capitalino en algunos casos) para entenderlo mejor a través de la observación relacional y comparada con otros casos. Apostamos por anclar esa perspectiva en el campo de la historia latinoamericana dada la pertenencia de Argentina a ese conjunto y las fuertes correlaciones existentes en el tema que nos ocupa, recurriendo a la historia conectada que une nuestro país al resto

5 En particular, el estudio de las "masacres" de comienzos del siglo XX ha sido patrimonio frecuente aunque no exclusivo- de una literatura de carácter denuncialista y militante más que académica, Entre otros, Bayer (1972-1974); Bilsky (1984); Frydemberg y Rufo (1992); Godio (1972); Perdía y Silva (2017); Silva (2011); Solans (2013); Vidal (2006).

6 Para una primera aproximación remitimos al lector a la lectura de trabajos sobre Brasil, Chile y Uruguay que componen el dossier de este número del Boletín. Desde luego esta mirada comparada podría ser extensiva mucho más allá de América Latina a pensar en general el ejercicio de la violencia estatal de los estados liberales modernos. Aquí nos limitamos a explorar la dimensión regional porque nos interesa un movimiento epistemológico tendiente a descentrar la explicación de la historia nacional. 
de la región, y la productividad del uso de la historia comparada con otros casos nacionales y regionales. Desde hace décadas existe un profuso desarrollo de la historia local y, en menor medida, de la historia trasnacional que conviene poner en relación para construir un problema y una mirada de largo plazo. Estas perspectivas han sido ensayadas para otros temas pero nos parecen poco exploradas para pensar la cuestión represiva -más allá de ciertos eventos específicos que mencionaremos luego-.

b) Periodizaciones. Partimos de la idea de que una adecuada comprensión de la historicidad de las formas de la violencia estatal del país requiere morigerar la separación en compartimentos historiográficos relativamente disociados entre quienes se dedican al estudio de la Argentina anterior a 1955 y de la historia posterior a ese año. Suturar esas separaciones y alentar el limitado diálogo entre unas y otras historiografías permitiría volver a discutir cuáles son los mejores cortes cronológicos y problematizadores para abordar la historia de las violencias de estado y hacerse algunas preguntas distintas, en particular en torno a algunos elementos que podríamos considerar continuidades represivas relativamente resistentes a los cambios de ciclos políticos. Este problema se relaciona de manera directa con el siguiente.

c) La "cuestión peronista”. Nos interesa discutir algunas de las consecuencias historiográficas del peso asignado a los conflictos entre peronistas y antiperonistas para explicar las derivas de las formas de la violencia estatal en la segunda mitad del siglo XX, así como el excesivo foco puesto en esa tensión como corte histórico.

Por último, al final del texto proponemos algunas ideas -más en tono de ensayo que de interpretaciones saldadas- para pensar las violencias represivas en la Argentina del siglo XX, alguna posible comparación y formas de periodización.

Tres últimas observaciones antes de entrar en materia. La primera es que este texto se reconoce explícitamente dentro del campo de la discusión historiográfica y no del campo de la investigación histórica que produce conocimientos empíricamente fundados. Aun sabiendo que entre ambos tipos de investigaciones hay múltiples conexiones, nuestra propuesta se concentra en el problema de las interpretaciones historiográficas y sus derivas o soportes más explícitamente políticos y no en la generación de resultados novedosos por la consulta a fuentes. En ese sentido, proponemos algunas hipótesis globales para el debate historiográfico con la esperanza de que puedan funcionar como balizas para (re)ingresar a la indagación empírica propiamente dicha. ${ }^{7}$ La segunda es que no escapará a los lectores que una pretensión tan amplia -como es construir un problema historiográfico en torno a la represión en el largo plazo- alienta la desestabilización de algunos consensos

7 Al mismo tiempo, nos concentraremos en grandes lineamientos de la discusión y por razones de espacio no podemos dar cuenta de toda la producción existente sobre modalidades, eventos o procesos represivos, por lo cual pedimos disculpas de antemano a todos los autores y autoras injustamente no mencionados aquí. 
interpretativos -tal como son la "cuestión peronista" a la hora de pensar la represión, o la disociación historiográfica entre la primera y segunda parte del siglo-, por lo que matices y ajustes quedarán inevitablemente como tareas a futuro. La tercera advertencia es que, si bien la voluntad de este artículo es ofrecer una discusión global sobre el siglo XX, nuestra práctica de investigación ha estado enfocada en la historia más reciente de la Argentina, por lo cual el lector tal vez encuentre aquí más énfasis, ejemplos o supuestos provenientes de ese tramo temporal.

\section{El problema de las escalas}

El campo disciplinar historiográfico argentino, al igual que el resto de las disciplinas sociales, contiene muchas asimetrías. Las jerarquías diferenciadas entre sujetos, grupos e instituciones son rasgos inevitables, dinámicos y estructurantes de los campos académicos si seguimos a Pierre Bourdieu, y no hay allí algún elemento particular del Río de la Plata. Otro de sus rasgos es la distribución territorialmente desigual del poder dentro del campo. Las instituciones académicas metropolitanas, aquellas asentadas en el corredor que va desde Mar del Plata en el sur, cruza por La Plata, el conurbano bonaerense, la ciudad de Buenos Aires y finaliza en Córdoba, pasando por Rosario, concentran la mayor parte de los practicantes de la disciplina, las revistas más prestigiosas, los espacios de consagración y el mayor nivel de exposición. Eso ha hecho que la historiografía más visible sea la que se produce en esas instituciones metropolitanas (no sucede nada distinto en Uruguay o en Chile: sí parece diverso o aminorado el panorama en Colombia o en Brasil). Ello ha conducido a que los estudios realizados con archivos "nacionales" y a la vez asentados en las áreas centrales del país sean los que poseen mayor capacidad para relatar, interpretar e imponer ciertas versiones sobre el pasado argentino. Por ello, como ya han señalado muchos colegas que investigan historia de espacios regionales (entre otros Bandieri y Fernández, 2017), el pasado que se suele presentar como "nacional" es muchas veces el resultado de extender de manera un tanto generalizante un conjunto de perspectivas que muchos llaman "porteño-céntrica". Esa caracterización que rige para diversas áreas temáticas también ha afectado al estudio de las violencias represivas de tres maneras específicas.

La primera es que -salvo ciertos temas puntuales como la represión dictatorialsabemos poco sobre las formas de represión y las prácticas de sujeción efectivamente desplegadas en las regiones periféricas, en las que los ciclos políticos y de violencia estatal que la historiografía reconoce como "nacionales" no alcanzan a dar cuenta de los fenómenos históricos en toda su complejidad (Bohoslavsky y Lvovich, 2017). Es claro que la escala nacional es crucial para la comprensión de la represión por cuanto la legislación penal y política que la avala y las fuerzas que la ejecutan normalmente corresponden al nivel nacional o federal. Sin embargo, por ejemplo, Ludmila Da Silva Catela (2010) mostró con suficiencia que el año 1976 no significa demasiado en la memoria de los campesinos de la Puna jujeña, para quienes el maltrato policial y de las autoridades locales, superpuesto con la violencia patronal contra las iniciativas y organizaciones de los trabajadores, han 
sido rasgos consuetudinarios más que una novedad de la última dictadura. En todo caso, el golpe de ese año agravó las formas de violencia física y simbólica -como han mostrado abundantes investigaciones sobre el período específico-, pero no las inventó (y podemos hipotetizar que la asunción de Alfonsín en 1983 tampoco las eliminó). ${ }^{8}$ En igual sentido, el cierre de los ingenios del noroeste argentino bajo la dictadura de Onganía modificó la estructura social y económica regional y desató un enorme conflicto social seguido de respuestas represivas, que han quedado desdibujados respecto del proceso dictatorial iniciado en 1976 -cuyas formas locales no se entienden sin esos otros procesos previos-. Por su parte, los tucumanos se baten incansablemente para que dejemos de utilizar ese año como el del inicio del terrorismo de Estado, ante la evidencia abrumadora de la brutal represión militar y paramilitar desplegada desde 1975 en esa provincia. Por sumar otro ejemplo de asincronías de la historia política "nacional" poco atendidas en las instituciones metropolitanas, la provincia de Santiago del Estero estuvo sometida al autoritarismo, la persecución policial y la violencia represiva antes y después de la última dictadura por la misma familia política, el "juarismo". Recordemos que Carlos Juárez fue juzgado por delitos de lesa humanidad cometidos en 1973, pero su hegemonía política en la provincia se extendió con altibajos entre 1949 y 2004 gracias a un aparato de control político superpuesto al Partido Justicialista santiagueño. ${ }^{9}$ Por tanto, solo con tomar los casos de Jujuy, Tucumán y Santiago del Estero a escala regional ya aparecen procesos represivos que difícilmente puedan explicarse sólo con el relato y la periodización "nacional" sobre las formas de la violencia estatal. Estos ejemplos muestran que los conflictos políticos y las prevenciones de las autoridades públicas sobre las diversas formas de disidencia política se han distribuido de manera regionalmente diversa en el siglo XX.

Entre otros fenómenos encontramos también entramados represivos orientados por la defensa de intereses empresariales localmente poderosos unidos a los gobiernos locales o provinciales. La fuerza de esos entramados explica, por ejemplo, bastante de la represión a los trabajadores asentados en actividades agroexportadoras de comienzos de siglo (el puerto de Buenos Aires, las estancias ovinas de Santa Cruz o los obrajes de "La Forestal"), pero también dinámicas represivas como la de la empresa Ford en el Gran Buenos Aires durante la última dictadura. ${ }^{10}$ Desde luego podría aducirse que se trata de fenómenos distintos a los de la represión directa del Estado pues obedecen a configuraciones históricas particulares como la debilidad estatal frente a los intereses empresariales -cuando no su evidente superposición-, pero no por ello deben quedar afuera de un mapa temporal y espacial de las violencias represivas, especialmente porque suelen ser

8 Véanse por ejemplo, los trabajos de Garaño (2011); Nassif (2016); Nemec (2019); Verbitsky y Bohoslavsky (2013) y las investigaciones sobre responsabilidad empresarial (FLACSO et al, 2015).

9 Juárez fue gobernador en cinco períodos: 1949-1952; 1973-1976; 1983-1987; 1995-1999 y 1999-2004. Varios de sus funcionarios de inteligencia y seguridad del periodo pos-dictatorial fueron condenados por haber cometido delitos de lesa humanidad durante la dictadura. Si bien Juárez fue víctima de la persecución dictatorial y debió exiliarse y su esposa estuvo presa, se considera que en la provincia existe fuerte continuidad de las estructuras represivas y de inteligencia antes, durante y después de la dictadura (Schnyder, 2013).

10 Para “La Forestal”, cfr. Jasinski, 2013. Para la empresa Ford, cfr. Basualdo, Ojea y Varsky, 2013. 
procesos poco visibilizados al estudiar los grandes procesos políticos nacionales desarrollados en ámbitos metropolitanos.

El segundo problema derivado del uso predominante de la escala nacional es la minimización de prácticas represivas orientadas por criterios (formalmente) no políticos sino étnicos, como las dirigidas a los pueblos originarios del norte y sur del país. La escasa atención de la historiografía -no así de la antropología- a los conflictos étnicos del siglo XX dificulta una incorporación de las violencias de estado desplegadas fuera de las zonas centrales del país a los ciclos políticos reconocidos por la historia "nacional". Sin establecer en absoluto una linealidad unívoca entre los conflictos, un eje de violencia racista conecta los campos de concentración de mapuche Valcheta en la década de 1880, las masacres de Napalpí en el Chaco en 1924 y la de Pilagá o Rincón Bomba en 1947 en el Territorio Nacional de Formosa, los procesos de proletarización forzada de las comunidades puneñas para trabajar en los ingenios azucareros salteños y jujeños y en las empresas forestales del Chaco santafesino, el enfrentamiento con la comunidad q'om por la desposesión de sus tierras durante las primeras décadas de los 2000 y el asesinato de Rafael Nahuel en 2017. De alguna manera, el desdibujamiento de esta violencia socio-étnica en el siglo XX cuando se estudian las pautas represivas del Estado argentino -sobre todo en el noreste más que en el sur- está ligado a la debilidad de los diálogos de nuestra disciplina con la antropología -menores que los que tradicionalmente ha tenido con la ciencia política o la sociología, al menos hasta fecha reciente-. ${ }^{11}$ Una mayor atención sobre el tema de parte de quienes estudiamos la represión estatal nos llevaría a percibir lo que los antropólogos y los etno-historiadores vienen mostrando hace mucho tiempo: por un lado, que la violencia estatal en ámbitos rurales tiene connotaciones etnizadas, que el problema del acceso a la tierra y al territorio por parte de los pueblos originarios y la ampliación de la frontera agrícola están en el corazón de las violencias desplegadas por un entramado que vincula a empresarios locales y/o extranjeros y a actores estatales y para-estatales (Delrio, 2010; Delrio et al. 2018; Pérez, 2016, Trinchero 2000). La sola presencia de esas violencias materiales y simbólicas pone en cuestión el relato nacional sobre el carácter "blanco" del país y el "crisol de razas" (Adamovsky 2009 y 2017) y pone en evidencia la dificultad que muchas veces se plantea para separar analíticamente las violencias estructurales producto de la desigualdad, la represión "social" y la represión "política". 12

El tercer problema es que todavía parece insuficiente la atención prestada a cómo los procesos internacionales y hemisféricos contribuyeron a configurar las formas represivas argentinas y a otorgarle sentidos, siempre disputados y cambiantes, pero nunca exclusivamente "nacionales". Las prácticas coercitivas argentinas tienen componentes y alcances nacionales, pero también otros de carácter continental e internacional que merecerían analizarse en su mayor interacción. Existen numerosos ejemplos ya explorados que sugieren la fecundidad

11 Con ese foco trabaja la Red de Investigadorxs en Genocidio y Política Indígena, integrada por antropólogos e historiadores que desde 2004 viene realizando esfuerzos para visibilizar esos procesos e integrarlos en una perspectiva más general sobre la historia argentina.

12 Sobre estas distinciones y sus complejidades, véase Lvovich (2020). 
de esa línea de indagación. La dimensión transnacional se pone en evidencia, por ejemplo, en la fuerte conexión y coordinación internacional que tuvo la persecución al anarquismo a inicios del siglo XX. El temor al "anarquismo violento" en la Argentina del Centenario fue también resultado de la mirada de las élites sobre la expansión y acciones de movimiento ácrata en Europa (Suriano, 2001). La Ley de Residencia, de expulsión de extranjeros, hito fundante de la represión estatal moderna en la Argentina, existió simultáneamente en Brasil (1907) y Chile (1918). Esa legislación dio lugar a una fuerte circulación de anarquistas, pero también a mayor y más eficiente coordinación de las agencias estatales dedicadas a su persecución (Albornoz 2017; Albornoz y Galeano, 2017). La reacción estatal y policial que desató la "Semana trágica" es inseparable del temor al avance del maximalismo y de los "soviets" en el Río de la Plata (Camarero, 2017). El miedo rojo de 1919 tuvo réplicas en Buenos Aires, Lima, Río de Janeiro, Puerto Natales y Montevideo, gracias a la circulación de temores compartidos por las elites, por las agencias policiales y las embajadas europeas asentadas en América del sur (Díaz, 2019; Lvovich, 2016). Por otro lado, el anticomunismo en la Argentina no fue un fenómeno de origen externo practicado por algunos grupúsculos marginales al juego político, sino un elemento relevante de los principales partidos políticos del siglo XX (cfr. Acha, 2014; Hudson, 2015; López Cantera, 2016/2017; Marengo, 2018). Pero las formas, temáticas y organizaciones anticomunistas argentinas fueron tributarias de preocupaciones, publicaciones, ideas, y a veces fondos, provenientes de afuera del país, en el largo ciclo que va de la primera posguerra a la desaparición del bloque soviético. Algunos de esos elementos transnacionales tal vez tuvieron un peso mayor en algunas regiones argentinas que en otras, tal como muestran las formas de control y espionaje de la policía bonaerense (Casola, 2017), la mendocina (Rodríguez Agüero, 2013) o la chubutense (Gatica 2013) sobre los exiliados chilenos en los años setenta. Y lo mismo ha sido mostrado en relación con las coordinaciones represivas de las dictaduras de los años setenta, cuyo pico fue el Plan Cóndor (Slatman, 2016).

No siempre es necesario ir en búsqueda de los datos evidentemente transnacionales para percibir estos factores, basta con interrogar a aquellos que en principio parecen estrictamente locales. Así, a pesar de que las historias político-institucionales de Argentina y Uruguay en el siglo XX han sido muy distintas, tanto el desarrollo doctrinario y jurídico de la legislación represiva como la construcción de representaciones sociales sobre los conflictos políticos guardan enormes semejanzas entre los dos países. En el Uruguay de 1967 a 1973 se vivió un proceso de socavamiento de las estructuras legales del estado de derecho y se instalaron y aplicaron formas represivas gracias a la confluencia de actores civiles y militares en el gobierno (Broquetas, 2014; Franco 2012a; Iglesias, 2010). Evidentemente, este "camino democrático a la dictadura" de Uruguay (Rico, 2006) tiene importantes similitudes con los años inmediatamente previos al golpe de Estado de 1976 en Argentina (Franco, 2012a). De la misma manera, otras "dictaduras de la seguridad nacional" instaladas en el Cono Sur muestran lógicas represivas y proyectos políticos con muchas similitudes con el régimen argentino, a pesar de que fueron el resultado de procesos históricos nacionales muy diversos. 


\section{El problema de las periodizaciones}

La historiografía de los procesos políticos suele recurrir a periodizaciones basadas en derroteros, cortes o desafíos a la institucionalidad política (golpes de Estado, elecciones, revoluciones, etc.). Y si bien el ingreso de la llamada "nueva historia política” (Malerba, 2010) ayudó mucho a morigerar esa tendencia gracias al establecimiento de nuevas preguntas, las matrices de la vieja historia política siguen funcionando, al menos para pensar el problema de la violencia estatal. Una periodización ya clásica del ciclo político argentino de 1930 a 1983 tiende a poner el acento en la alternancia de tipos de regímenes (dictadura, luego democracia, luego dictadura...) asociados al predominio de un tipo de actor (Fuerzas Armadas, partidos políticos, Fuerzas Armadas...) Esta periodización atraviesa el lenguaje escolar y las referencias públicas habituales sobre el pasado nacional. ${ }^{13}$ Ella plantea -explícita o implícitamente- la existencia de regímenes políticos mutuamente excluyentes, puesto que la democracia no parecería tener ninguno de los rasgos que caracterizan los regímenes autoritarios y militares porque se asienta en la legitimidad constitucional y electoral de las autoridades (aun cuando el respeto a la formalidad electoral no estuvo garantizado en contextos de proscripción del peronismo entre 1955 y 1973 ni en trayectos de la década de 1930 bajo la proscripción de los radicales). Aunque el tema requeriría una indagación más precisa, esta matriz interpretativa ya estaba visible en trabajos seminales en los años ochenta como el de Marcelo Cavarozzi (1983) ${ }^{14}$, y terminó de conformarse con (y formar parte de) el discurso refundacional con que se instaló la democracia en 1983. Como hoy sabemos, eran interpretaciones de la democracia y para la democracia, pues estaban plagadas de un anhelo fundacional y de lecturas a veces ingenuas, voluntaristas y culturalistas sobre la capacidad argentina para vivir sin recurrir a la violencia política. Suponían que con la asunción del presidente Alfonsín se había lanzado una nueva etapa en la vida histórica argentina y que el mantenimiento y consolidación en el tiempo de la democracia requería que los principales actores políticos -pero también los académicos- desplegaran comportamientos consensuales, que desdeñaran los enfrentamientos totalizantes de antaño y que reconocieran o establecieran en diciembre de 1983 un punto de no retorno, de diferenciación irreversible respecto del pasado inmediato (Lesgart, 2003). Esta periodización canónica presenta al autodenominado "Proceso de Reorganización Nacional” como el momento de máxima violencia a la vez que indica que el tiempo posterior a 1983 habría invertido esos rasgos (o al menos tenía la misión histórica de hacerlo).

Se trata, claro está, de una periodización para comprender la vida política en general y muy útil para entender ciertos procesos, pero posee una serie de implicancias

13 En buena medida durante los años noventa las autoridades educativas nacionales y provinciales acompañaron esa idea a través de la noción de que la enseñanza de la historia debería coadyuvar a la formación de un alumno y futuro ciudadano democrático (González, 2014).

14 En la introducción de Autoritarismo y democracia, Cavarozzi (1983) señala sus diferencias con respecto a las interpretaciones previas sobre ese vaivén permanente y del que el país no habría podido salir. Cavarozzi propone la idea de que esa oscilación contuvo un crescendo de violencia política que forzaba a que cada fase fuera más fundacional y más extrema que la anterior (al punto que las democracias en realidad eran "semi-democracias"). 
para historizar la violencia represiva. Ésta aparece como un rasgo predominante de los regímenes dictatoriales, mientras que, en contraste, las democracias son caracterizadas -aunque sea implícitamente- por un uso más acotado, residual, ocasional y periférico de los recursos coactivos estatales para resolver los conflictos políticos. Por ello, en esta interpretación sobre el péndulo histórico argentino, la violencia estatal suele quedar asociada a un actor -las Fuerzas Armadas- y a una forma de intervención -la acción institucional de los militares-, y se desatienden otras formas de la represión estatal legalizadas o clandestinas, menos atadas a los ciclos políticos "nacionales".

Contrariamente a esta idea, al poner el ojo en el problema de la violencia estatal represiva, parecería aconsejable suspender -no disolver ni ignorar- las distinciones auto-explicativas entre dictadura y democracia, dado que ambos tipos de régimen no siempre mostraron diferencias obvias en cuanto a la gestión del conflicto político y social. Así, es posible encontrar que en distintos momentos autoridades militares y civiles pensaron, enfocaron y articularon prácticas bastante similares para enfrentar las supuestas amenazas al orden social, con relativa independencia de si su cargo descansaba en un origen electoral o una cuartelada. Dentro de cada ciclo histórico largo pueden encontrarse continuidades entre las prácticas, los discursos y la legislación represiva más allá de los cortes institucionales y los regímenes políticos, e incluso a lo largo del siglo hubo permanencias significativas, como los instrumentos simbólicos movilizados para enfrentar diversos conflictos y legitimar los entramados represivos con que se respondió a ellos. Entre 1955 y 1983 hay procesos con cierta continuidad y acumulación en la imposición de los principios de la seguridad nacional como ideología permanente de los gobiernos. Y si bien esos dispositivos y prácticas represivas fueron diversos, cambiantes, con momentos de aceleración y de freno, permanencia y diferenciación entre unos y otros gobiernos, son partes de un proceso en el que las democracias (restringidas y tuteladas) no fueron garantía de menor coerción política (Franco, 2016). El crecimiento de las prácticas y dispositivos represivos a finales de los años cincuenta y los setenta fue legitimado por una mirada muy difundida sobre la amenaza (peronista, marxista y/o subversiva) contra la "seguridad nacional", algo que Frondizi, Onganía y el último Perón compartían en buena medida (Franco, 2012b). El Plan Conintes (Conmoción Interna del Estado) puesto en marcha por el gobierno de Arturo Frondizi en 1960 es, sin duda, un buen ejemplo de ello y hasta ahora ha tenido mucha menos atención historiográfica de lo que su importancia reclama. ${ }^{15}$ Los gobiernos de Frondizi (1958-1962) y de Perón y luego Martínez de Perón (1973-1976) se distinguieron por la implantación de auténticos estados de excepción y por la persecución política sistemática a través de articulaciones complejas entre formas legalizadas y clandestinas de represión política y social. El proyecto de ley de defensa promovido por el presidente Frondizi fue retomado por el gobierno de Illia, promulgado por el dictador Onganía (Ley de Defensa Nacional, $n^{\circ}$ 16970/66) y luego aplicado por el presidente Perón (junto con otras legislaciones nuevas del mismo tenor) y se mantuvo en vigor hasta 1988 (Franco 2012a; 2012b; Pontoriero, 2012). En un sentido similar, los aportes provenientes 
de la historia de las agencias estatales encargadas de la acción represiva -sus saberes, sus lógicas de autonomización y profesionalización, sus prácticas, los vínculos entre administración, técnica y política, etc.-, muestran procesos para los cuales las periodizaciones habituales resultan poco útiles. Así, la documentación producida y almacenada por la Dirección de Información de la Policía de la Provincia de Buenos Aires (DIPBA) entre los años cuarenta y noventa pone en cuestión la idea de que eran muy distintas las formas de persecución al comunismo llevadas adelante por gobiernos "democráticos" o "autoritarios" de las décadas del cuarenta al sesenta (Marengo 2018). Lo propio ocurre con las inquietudes de la policía bonaerense y sus sospechas sobre los trabajadores chilenos desde los cincuenta y hasta los ochenta (Pérez Álvarez y Gatica, 2020).

Como ya señalamos, nuestra invitación a ver las prácticas y discursos de la represión del siglo XX incluye también incorporar al análisis los años posteriores a 1983. La historiografía argentina tiene enormes dificultades para deconstruir el “momento 1983” como el mito de inicio que representa, más allá de los cambios históricos indiscutiblemente acaecidos. Superar ese Rubicón historiográfico es tan complicado como necesario porque sobre él recae parte de la construcción de la excepcionalidad argentina en relación con el resto de la región en lo que atañe a la historia más reciente: la investigación y juzgamiento de las violaciones a los derechos humanos del pasado -en contraste con la impunidad brasileña, con la limitada justicia uruguaya o aún con la discreta chilena-. Avanzar en el estudio histórico de las formas de gestión represiva del conflicto social y político de los años ochenta y noventa permitirá obtener una idea más acabada de esta violencia, sus altibajos, variaciones y diferencias durante el período más largo de vigencia del Estado de derecho. Un ejemplo claro de ello es la represión utilizada como política de disciplinamiento ante las resistencias de trabajadores, jubilados o estudiantes, entre muchos otros, a las políticas públicas neoliberales desde fines de los años noventa en adelante. Al ingresar en este período parece necesario poner en diálogo las violencias represivas que nos interesa estudiar con aquellas otras más ordinarias, menos políticas en sentido estricto, y más propias de las formas regulares de gestión estatal de los desvíos de la norma. Así el crecimiento de la llamada "violencia institucional" y en particular la violencia policial, con target sobre los jóvenes pobres, es seguramente una de las marcas distintivas de los últimos treinta años de historia argentina -como en Colombia y Brasil-- ${ }^{16}$

En la misma línea, "el 2001” constituye un objeto impensado para la historiografía de la represión, no sólo por su cercanía temporal sino porque se lo lee como parte de otro orden de acontecimientos vinculados a la irrupción de una crisis inesperada y de nuevo tipo (Pereyra, Vommaro y Pérez, 2013). Pero la novedad política que efectivamente contuvo ese año y el ciclo político posterior a 1983 al que pertenece, no debería ocultar que desde el punto de vista del Estado constituye un episodio que osadamente podríamos alinear con otros eventos como los choques del Centenario, la "Semana trágica” de 1919, los fusilamientos de 1956 o

16 Vale la pena señalar que las formas de la violencia estatal posteriores a 1983 han sido objeto privilegiado de la antropología, y en menor medida de la sociología, disciplinas que suelen trabajar con menos eslabonamientos con procesos represivos del pasado (Sain, 2008; Tiscornia, 2016). 
las víctimas del Rosariazo de 1969 -siempre bajo la condición de entender cada episodio situadamente como parte de conflictos y relaciones de fuerzas específicas-. A la vez, las decenas de muertos de aquellos días finales de 2001 y el dato, notable, de que la protesta social desafiara el estado de sitio, tan recurrentemente disciplinador en la historia argentina del siglo XX, merecen integrar la serie precedente para constituir parte de lo que debe ser explicado, incluso para marcar las diferencias de ciclo político y configuración de fuerzas, agentes, tipologías, víctimas y dispositivos.

Desde luego, los asesinados tras el ataque al Regimiento de La Tablada en 1989 y los fusilados en Trelew en 1972 no son resultado de un mismo patrón represivo, pero tampoco podemos asumir que entre ellos todo es diferencia. ¿Qué distancia de manera decisiva las desapariciones de los cuerpos de Joaquín Penina en 1930, de Juan Ingalinella en 1955, de Felipe Vallese en 1962 y de Miguel Bru en 1993 ? ¿Qué sugiere el carácter coyuntural de cada uno de estos hechos y la existencia de similitudes entre los episodios? ¿Constituyen una serie pasible de ser analizada como tal? ¿Se trata de un dispositivo específico o existen series similares en otros países? Insistimos en que no deseamos "achatar" los datos como parte de un interminable martirologio popular del siglo XX ni de asociar eventos estructuralmente distintos -como un cuerpo muerto bajo la habitual tortura policial y el sistema de desaparición forzada de los años setenta-, sino de recuperarlos como problemas tan específicos como recurrentes, que alumbran funcionamientos sociales y estatales a ser explicados en sus claves de época particulares, dentro de ciclos históricos locales, nacionales e internacionales específicos.

\section{Los lugares del peronismo y del antiperonismo}

Otra periodización, y que ha asumido mayor fuerza interpretativa en los últimos años coloca la cesura política clave del siglo XX en 1955. De hecho, el propio campo de la historia reciente en la Argentina tiende a situar su frontera difusa en ese año. Sin abandonar el peso de la alternancia entre democracia y autoritarismo, la bisagra en este caso sería la existencia de un ciclo específico de extrema violencia política que se iniciaría con la caída del primer peronismo y se habría cerrado -eso sí, también- en 1983. Ese ciclo comenzado con los bombardeos de la Plaza de Mayo se habría acelerado con la agudización del conflicto entre peronismo y antiperonismo (y entre sus fracciones), la radicalización política de fines de los años sesenta, y luego habría alcanzado su paroxismo en la última dictadura con la máxima aplicación de violencia estatal y para-estatal conocida en la historia argentina. Esta interpretación historiográfica contiene, muchas veces, cierto rasgo teleológico por cuanto supone que todo lo ocurrido desde 1955 condujo inevitablemente a un crescendo de violencia: un hilo rojo uniría los fusilamientos de los basureros en José León Suárez en junio de 1956 con los vuelos de la muerte salidos de la ESMA veinte años después. Una parte de la historiografía argentina ha otorgado un gran peso al conflicto entre los peronistas y los antiperonistas para entender la dinámica política de la segunda mitad del siglo XX, al 
punto de devenir una variable explicativa fundamental de la historia posterior a 1955. En efecto, desde 1943 el peronismo irrumpió y con ello modificó en forma permanente e irreversible la escena social y política argentina. Tampoco debe negarse que, efectivamente, los conflictos con sus opositores fueron y son parte del escenario argentino hasta la actualidad y en los últimos quince años esta línea interpretativa se profundizó en la medida en que las tensiones políticas suscitadas bajo los gobiernos kirchneristas (2003-2015) reactualizaron esa matriz de lectura. Oficialistas y opositores proyectaron hacia atrás su antagonismo para iluminar selectivamente al pasado y con ello resignificar los conflictos del presente. La interpretación de la llegada de Cambiemos al Poder Ejecutivo Nacional en 2015 como un "nueva Libertadora", o la sentencia macrista sobre los errores económicos de los "últimos setenta años" ejemplifican buena parte de ello. ${ }^{17}$ En todo caso, es pertinente preguntarse si la centralidad explicativa asignada a esas tensiones -por ejemplo durante los gobiernos de Frondizi, de Onganía o el último de Perón- no minimizó el peso que tuvieron otros elementos en la configuración de los conflictos sociales y políticos y las formas de violencia con las que el Estado respondió a ellos.

Veamos las consecuencias de esta cuestión. En primera instancia, la tendencia a poner el acento en la persecución al peronismo a partir de 1955 ha desdibujado la persecución política realizada por el propio gobierno peronista durante su primera década en el poder, incluyendo dispositivos claves de la época como la creación en 1943 de la Policía Federal Argentina, el uso de la prisión política, la censura y la limitación de libertades. Con notables excepciones como los trabajos de Kabat (2017) sobre políticas represivas del peronismo; de Piliponsky (2014) sobre la huelga azucarera de 1949, de Marengo (2018) sobre la persecución policial al comunismo y de Nazar (2008) sobre el uso de la Ley de Residencia, la relación entre peronismo "clásico" y la represión estatal aún requiere una indagación sistemática.

En segundo lugar, podríamos ver, por ejemplo, que la matriz nacionalista y xenófoba que legitimó la práctica represiva de la segunda parte del siglo XX y que suele ser asociada a la Guerra Fría y la doctrina de la guerra contrarrevolucionaria, estaba ya presente en la persecución al anarquismo y al movimiento obrero en las tres primeras décadas del siglo. Ello deja a la vista un sistema de representaciones sociales y culturales bastante estable y usado para definir enemigos políticos a lo largo de buena parte de la centuria (Franco, 2019). Por otro lado, la participación militar en la represión de la "Semana trágica" en 1919 y su impacto sobre la propia corporación armada, es fundamental para comprender el proceso de intervención y presión militar sobre el juego político posterior a 1930 (Forte, 2004). En igual sentido, la declarada intención del presidente Macri de otorgar funciones de seguridad interior a las Fuerzas Armadas (Decreto 683/18): ¿es una rareza del ciclo político posterior a 1983 o es más bien el regreso de una añeja tradición del siglo XX argentino, iniciada como mecanismo de solución de

17 En una línea claramente humorística lo presentó el dibujante Miguel Rep en el marco del Bicentenario cuando lanzó un libro sobre 200 años de peronismo. Rep (2010). 
conflictos económicos -en 1879- y políticos -en 1919-?, ¿qué lugar darle a esa "tradición" en constelaciones de poder y regímenes socio-políticos tan distintos de la primera y segunda parte del siglo?

En tercer lugar, consideramos que la propia historia de las disputas entre el peronismo y el antiperonismo en la segunda mitad del siglo XX no puede ser entendida por fuera de la Guerra Fría. Las tensiones internacionales generadas por el conflicto bipolar se instalaron dentro del propio movimiento peronista, empujando sus dinámicas internas en los años setenta a formas agudas de violencia (Franco, 2012a). Los peronistas leyeron sus tensiones intestinas usando esa clave interpretativa (Bohoslavsky y Vicente, 2014). La "Revolución Libertadora", el hecho antiperonista por antonomasia, también debería ser leído como parte de un marco internacional atravesado por las múltiples dimensiones, influencias y diálogos (Galván y Osuna, 2018). Las políticas represivas del frondizismo se iniciaron como reacción a la oposición obrera a las privatizaciones petroleras, no a la "resistencia peronista". El estado de sitio permanente se impuso para garantizar la ejecución del plan desarrollista y no para reducir el peso electoral del neoperonismo (Franco, 2012b). El posterior golpe de Estado contra Frondizi estuvo basado en el miedo a una insurrección comunista inspirada en Cuba, no a un avance del peronismo (Hudson, 2015). Estos datos nos recuerdan, entonces, que es necesario volver a ponderar el peso que a veces se le otorga al conflicto político centrado en la "cuestión peronista" -cuando se tiende a transformarlo en explicación únicay asumir que los conflictos que involucraron a la clase trabajadora no siempre tuvieron vinculación con alguna forma de identificación peronista. Difícilmente "el Cordobazo", proceso fundante de una "nueva izquierda" argentina (Tortti, 2004) y que enciende definitivamente las alarmas militares sobre el conflicto social (Pontoriero, 2017) obedece a conflictos propios de la "cuestión peronista". Frente a procesos asimilables y comparables ocurridos en otros países por las mismas décadas, ¿cómo medir entonces, el peso de la "cuestión peronista" en el advenimiento de las formas más extremas de la violencia estatal en la Argentina? Es evidente que la organización Montoneros no habría tenido el alcance político y geográfico que alcanzó ni su impacto posterior si no hubiera surgido identificada con y dentro del peronismo, pero su propia historia se inscribe también en un ciclo regional y epocal revolucionario del Cono Sur.

\section{Recapitulaciones y propuestas}

En este artículo hemos discutido algunos marcos de lectura habituales sobre el problema de la violencia estatal en la Argentina con la intención de repensar de manera integral e integrada esa cuestión a lo largo del siglo XX. Para ello, hemos sugerido la utilidad de a) desnaturalizar más y mejor las escalas nacionales y de prestar atención a las articulaciones entre las dimensiones locales, regionales y transnacionales. Un diálogo más intenso con la historia latinoamericana y regional permitiría hacerse más y mejores preguntas sobre los fenómenos nacionales y ponderar con mayor precisión los factores que consideramos esenciales para 
explicarlos; b) desafiar las periodizaciones más frecuentes que disocian la primera y segunda parte del siglo XX; c) deconstruir el presupuesto de que los gobiernos constitucionales de este siglo no recurrieron al ejercicio de formas extremas y legalizadas de violencia estatal, y d) ofrecer mejores articulaciones explicativas con la historia latinoamericana y global para dimensionar con mayor precisión la "cuestión peronista" como elemento explicativo central de la violencia estatal durante la Guerra Fría.

¿Podemos pensar, a la vez, en rasgos recurrentes y generales, en ciclos históricos diferenciados de conflictividad política y social y en formas diversas de la represión estatal que hagan inteligible esa violencia como un problema de estudio? Es importante insistir en la idea de que tener un problema historiográfico unificado no significa sólo registrar continuidades históricas. Por el contrario, construir un problema historiográfico significa pensar y detectar las manifestaciones históricas en cada momento. Vista la centuria en toda su amplitud, difícilmente podría sostenerse que la violencia estatal fue un rasgo sobresaliente sólo de los procesos posteriores a 1955. Episodios como la "Semana roja" de 1909, la "Semana trágica" de 1919, los fusilamientos en Santa Cruz en el verano de 1921 y 1922, o la represión en las grandes compañías agroexportadoras de "La Forestal" (1919-1922) o "Las Palmas" (1920), así como las numerosas formas legales e ilegales de las que se sirvió el Estado para perseguir a las izquierdas, al sindicalismo e incluso al radicalismo en los años treinta y luego bajo el primer peronismo, nos invitan a calibrar mejor el foco excesivamente colocado en la segunda parte del siglo (y lo propio puede decirse de la continuidad de la represión orientada hacia los pueblos originarios). Más allá de las dinámicas y parcelamientos propios de la investigación que en general se aboca a tramos temporales cortos, la pregunta que a nuestros ojos permanece en pie es ¿por qué unos y otros hechos y procesos no suelen ser integrados en las miradas de la historiografía académica en pos de construir un problema integrado?, ¿cuánto del acento puesto en la "cuestión peronista” y en la violencia política posterior a 1955 nos impide ver articulaciones, continuidades, diferencias, y recortar un problema analítico integral con perspectivas de largo plazo? Las posibilidades y sentidos que trajo el despliegue de la Guerra Fría (y sus particulares relecturas locales) modelaron dispositivos, lógicas y formas de intervención diferentes a los anteriores. Pero esas modificaciones no nacieron con la partida al exilio de Perón y en todo caso, después de esa fecha la existencia de un péndulo entre (semi)democracia y dictadura poco ayuda a entender el despliegue creciente de las formas legales e ilegales de represión. No se trata de minimizar datos muy conocidos de la escena política nacional (como la persecución a grupos y sindicatos peronistas en los años sesenta), sino de articularlos con otras escalas para producir interpretaciones más atentas a la multiplicidad de procesos y conflictos que confluyen de forma simultánea y desordenada.

Introducir la perspectiva de la historia latinoamericana en clave comparativa abre un panorama distinto sobre muchos aspectos de la conflictividad social y de la violencia estatal argentinas. En efecto, un aspecto compartido de Argentina con el caso uruguayo y el colombiano, por lo menos desde mediados del siglo XX, parece ser la intensidad del conflicto más estrictamente político -y el predominio de la 
violencia explícitamente política- respecto del peso de los choques abiertos entre grupos y fracciones de clases, como sí pueden identificarse en algunos países de América central -aunque desde luego la dimensión de clase siempre sea inseparable del conflicto-. A su vez, las tensiones religiosas, sin estar ausentes, no tuvieron la tonalidad dramática ni la masividad que alcanzaron la Guerra cristera de México en los años veinte o las recurrentes guerras civiles de Colombia o de Ecuador del siglo XIX. Estas comparaciones ayudan a pensar grandes ciclos o momentos distintos de nuestra historia. Así, las primeras décadas del siglo se caracterizaron de manera sobresaliente (pero no exclusiva) por una violencia represiva de clase, descargada principalmente sobre obreros y pobres -tanto urbanos como rurales- con fuerte racialización y tono xenofóbico en muchos casos. Este rasgo tampoco inhibió el uso de la represión contra ciertas élites políticas, como muestra el uso frecuente de las intervenciones provinciales o el sofocamiento de la revolución radical de 1905. En cambio, la violencia estatal de raíz claramente política y con escenario urbano fue central a partir de los años treinta y especialmente en la segunda parte del siglo (sin que desaparecieran otras formas de violencia, por supuesto). Esta lectura es tentadora para proponer una hipótesis rápida: que estos ciclos diferentes y la irrupción de la violencia más propiamente política a partir de 1930 podría ser un resultado de la llegada al poder de gobiernos con proyectos de democratización social y política como fueron el yrigoyenismo en 1916 y el peronismo en 1945. Es decir, cuando ambos proyectos políticos comenzaron a disputar la participación y lógicas de gobierno en favor de sectores sociales medios y populares, antes excluidos del poder, las reacciones conservadoras a esas novedades pasaron a tener como escenario el Estado y la persecución dentro del sistema político. Ello contribuiría a explicar los golpes de 1930 y de 1955 como reacciones a gobiernos que representaron formas de democratización y ampliación política. Sin embargo, esta explicación no resuelve un hecho central: los propios gobiernos democratizadores también impulsaron durante su ejercicio políticas represivas de distinto tenor e intensidad. En todo caso, sí sugiere un elemento a considerar para entender el pasaje a otro tipo de violencia en la que el escenario de disputa fue el Estado y los bandos se definieron por sus alineamientos políticos (partidarios o no).

Finalmente, un elemento notable al mirar de conjunto el siglo XX es la relativa autonomía de la violencia contra los grupos indígenas en relación con los ciclos políticos. Esa autonomía deriva de la presencia constante de ese tipo de violencias y no de que cada configuración de fuerzas y cada ciclo político respondan siempre de la misma manera a esos actores. En todo caso, este tipo de violencia constituye un hilo invisibilizado y relativamente constante que, más allá de sus modulaciones y variaciones, también se engarza con esas otras formas racializadas de la violencia estatal que afectan estructural y cotidianamente a numerosos habitantes de la Argentina. Recorrer el hilo de la violencia étnica nos obligaría a comenzar una periodización específica que, al menos para el Estado Nación moderno, tendría su momento fundante en las primeras masacres indígenas realizadas por un Ejército ya "nacional" a fines del siglo XIX, cuya acción disciplinadora no se detuvo en el aniquilamiento físico. Desde luego esta serie histórica nos acerca más a nuestra condición de país latinoamericano que otras dinámicas políticas, nacionales y urbanas. 
En síntesis, hemos intentado mostrar a lo largo de estas páginas que el estudio de la violencia represiva estatal en sus múltiples formas y dimensiones es un campo de preguntas y problemas que requiere de mucho trabajo colectivo y acumulado. Para ello es necesario, ante todo, la adecuada construcción de un objeto analítico al cual podamos formularle preguntas históricas generales, específicas y desnaturalizadas que coloquen bajo estricta vigilancia nuestros propios presupuestos historiográficos y políticos. 


\section{Bibliografía}

" Acha, O. (2014). El peronismo y la forja del anticomunismo obrero. Cuarto Congreso de Estudios sobre el Peronismo (1943-2014), Universidad de Tucumán.

" Adamovsky, E. (2009). Historia de la clase media argentina: Apogeo y decadencia de una ilusión, 1919-2003. Buenos Aires: Planeta.

" Adamovsky, E. (2017). Ethnic nicknaming: 'negro' as a term of endearment and vicarious blackness in Argentina. Latin American and Caribbean Ethnic Studies; 12; 3; 9; pp. 273289.

" Águila, G. (2018). La represión en la historia reciente como objeto de estudio: problemas, novedades y derivas historiográficas. En Águila, G. et al., La historia reciente en Argentina. Balances de una historiografía pionera en América Latina. Buenos Aires: Imago Mundi.

" Albornoz, M. (2017). Policías, cónsules y anarquistas: la dimensión transatlántica de la lucha contra el anarquismo en Buenos Aires (1889-1913). Iberoamericana, v 17, n. 64, pp. 57-79.

" Albornoz, M. y D. Galeano (2017). Anarquistas y policías en el Atlántico sudamericano: una red transnacional, 1890-1910. Boletín del Instituto de Historia Argentina y Americana "Dr. Emilio Ravignani", 47, pp. 101-134.

"Andersen, M. E. (2002). La Policía. Pasado, presente y propuestas para el futuro. Buenos Aires: Sudamericana.

" Archivo Nacional de la Memoria (2014), Plan Conintes. Represión política y sindical, Ministerio de Justicia y Derechos Humanos de la Nación.

" Bandieri, S. y S. Fernández (2017). Presentación. En su compilación La historia nacional en perspectiva regional. Nuevas investigaciones para viejos problemas, tomo I. Buenos Aires: Teseo.

" Basualdo, V.; T. Ojea Quintana y C. Varsky (2013). Los casos de Ford y Mercedes Benz. En Verbitsky, H., y Bohoslavsky, J. P. (comp.) Cuentas pendientes. Los cómplices económicos de la dictadura. Buenos Aires: Siglo XXI.

" Bayer, O. (1972-1974). Los vengadores de la Patagonia Trágica, Buenos Aires; Galerna.

" Bayer, O. (coord.) (2006). Historia de la crueldad argentina. Tomo I: Julio Argentino Roca. Buenos Aires: Centro Cultural de la Cooperación.

" Bilsky, E. (1984). La semana trágica. Buenos Aires: CEAL, 1984.

" Bohoslavsky, E. y D. Lvovich (2017). La historia reciente argentina a escala regional (19731983). En Bandieri, S. y S. Fernández (eds.), La historia nacional en perspectiva regional. Nuevas investigaciones para viejos problemas, tomo I. Buenos Aires: Teseo, pp. 215-238.

" Bohoslavsky, E. y M. Vicente (2014). Sino el espanto. Temas, prácticas y alianzas de los anticomunismos de derecha en Argentina entre 1955 y 1966. Anuario del Instituto de Historia Argentina, 14, pp. 1-17.

"Broquetas, M. (2014). La trama autoritaria: derechas y violencia en Uruguay (1958-1966). Montevideo: Ediciones de la Banda Oriental.

"Camarero, H. (2017). Tiempos rojos. El impacto de la revolución rusa en Argentina. Buenos Aires: Sudamericana.

" Casola, N. (2017). Los indeseables. El exilio chileno en la mirada de la DIPBA (1973-1983). 
Clepsidra, vol. 4, pp. 50-67.

" Cavarozzi, M. (1983). Autoritarismo y democracia, 1955-1983. Buenos Aires: CEAL.

" Da Silva Catela, L. (2010). Pasados en conflicto. De memorias dominantes, subterráneas y denegadas. En E. Bohoslavsky et al. (eds.), Problemas de historia reciente del Cono Sur. Buenos Aires: Universidad Nacional de General Sarmiento, tomo I.

" Delrio, W, Escolar, D, Lenton. D. y M. Malvestitti, dir. (2018). En el país de nomeacuerdo. Archivos y memorias del genocidio del Estado argentino sobre los pueblos originarios, 1870-1950. Viedma: Universidad Nacional de Río Negro.

" Delrio, W. (2014). Del no evento al genocidio. Pueblos originarios y políticas de estado en Argentina. EADEM Utraque Europa. 6(10-11), pp. 219-254.

" Díaz, H. (coord.) (2019). Espionaje y revolución en el Río de la Plata. Los archivos secretos de una red diplomática de persecución al maximalismo. Buenos Aires: Imago Mundi.

" Finchelstein, F. (2008). La Argentina fascista. Buenos Aires: Sudamericana.

" FLACSO, CELS, PVJ y SDH (2015) Responsabilidad empresarial en delitos de lesa humanidad. Represión a trabajadores durante el terrorismo de estado. Buenos Aires: Infojus.

" Forte, R. (2004). La "semana trágica" de 1919: crisis liberal, protesta social y fortalecimiento del poder militar en Argentina. En M. Ortega Soto, J. C. Castañeda y F. Lazarín Miranda (comps.), Violencia: estado y sociedad, una perspectiva histórica. México: Miguel Ángel Porrúa y Universidad Autónoma Metropolitana, pp. 59-88.

" Franco, M. (2012a). Un enemigo para la nación. Orden interno, guerra y subversión, 19731976. Buenos Aires: FCE.

"Franco, M. (2012b). Rompecabezas para armar: la seguridad interior como política de Estado en la historia argentina reciente (1958-1976). Contemporánea, 2, pp. 77-96.

"Franco, M. (2016). La represión estatal en la historia argentina reciente: problemas, hipótesis y algunas respuestas tentativas. En: G. Águila, S. Garaño y P. Scatizza (eds.), Violencias de Estado. Formas y dinámicas represivas en la historia reciente argentina: nuevos abordajes a 40 años del Golpe de Estado. Buenos Aires: UNLP, pp. 15-43.

"Franco, M. (en prensa). La guerra fría, cincuenta años antes. Prismas. Revista de Historia intelectual.

" Franco, M. y D. Lvovich (2017). Historia reciente: apuntes sobre un campo de investigación en expansión. Boletín del Instituto de Historia Argentina y Americana "Dr. Emilio Ravignani", 47, pp. 190-217.

" Frydenberg, J. y M. Rufo (1992). La semana roja de 1909. Buenos Aires: CEAL.

" Galván, M. V. y M. F. Osuna (comps.) (2018). Introducción. En su compilación La 'Revolución Libertadora' en el marco de la Guerra Fría. La Argentina y el mundo durante los gobiernos de Lonardi y Aramburu. Rosario: Prohistoria, pp. 13-22.

" Garaño, S., (2011) El monte tucumano como "teatro de operaciones": las puestas en escena del poder durante el Operativo Independencia (Tucumán, 1975-1977), Nuevo Mundo Mundos Nuevos.

" Gatica, M. (2013). ¿Exilio, migración, destierro? Trabajadores chilenos en el noreste de Chubut (1973-2010). Buenos Aires: Prometeo Libros.

" Godio, J. (1972). La Semana Trágica de enero de 1919. Buenos Aires: Hyspamérica.

" González Calleja, E. (2006). Sobre el concepto de represión. Hispania Nova. Revista de Historia Contemporánea, № 6 (sin paginar). 
" González, M. P. (2014). La historia argentina reciente en la escuela. Saberes y prácticas docentes en torno a la última dictadura. Los Polvorines: Universidad Nacional de General Sarmiento.

" Halperin Donghi, T. (1987). El espejo de la Historia. Problemas argentinos y perspectivas latinoamericanas. Buenos Aires: Sudamericana.

" Hudson, C. (2015). Cuba y el pánico derechista: ¿el derrocamiento de Frondizi es un golpe anticomunista o antiperonista?. En Bohoslavsky, E. y O. Echeverría (eds.) Las derechas en el Cono Sur, siglo XX. Actas del sexto taller de discusión, Los Polvorines, pp. 44-64.

"Iglesias, M. (2010). La excepción y la regla. Estado, partidos políticos y medidas prontas de seguridad en Uruguay 1946-1963. Tesis de la Maestría en Ciencias Sociales, Instituto del Desarrollo Económico y Social y UNGS, Buenos Aires.

" Jasinski, A. (2013). Revuelta obrera y masacre en La Forestal: sindicalización y violencia empresaria en tiempos de Yrigoyen. Buenos Aires: Biblos.

" Kabat, M. (2017). PérónLeaks. Una re-lectura del peronismo a partir de sus documentos secretos, 1943-1955. Buenos Aires: Ediciones ryr.

" Larraquy, M. (2017). Argentina, un siglo de violencia política. Buenos Aires: Sudamericana.

"Lesgart, C. (2003). Usos de la transición a la democracia: Ensayo, ciencia y política en la década del '80. Rosario: Homo Sapiens.

" López Cantera, M. (2016/2017). El anticomunismo argentino entre 1930 y 1943. Los orígenes de la construcción de un enemigo. The International Newsletter of Communist Studies, XXII/XXIII, N²9-30.

" Lvovich, D. (2016). La Semana Trágica en clave transnacional. Influencias, repercusiones y circulaciones entre Argentina, Brasil, Chile y Uruguay (1918-1919). En J. F. Bertonha y E. Bohoslavsky (eds.) Circule por la derecha. Percepciones, redes y contactos entre las derechas sudamericanas, 1917-1973. Buenos Aires: Universidad Nacional de General Sarmiento, pp. 21-40.

" Lvovich, D. (2020) La violencia dictatorial y la violencia estatal de largo plazo en el Cono Sur de América Latina: entre lo excepcional y lo habitual. Historia: Questões \& Debates, vol. 68, núm. 1, pp. 85-108.

" Malerba, J. (2010). La historia en América Latina. Ensayo de crítica historiográfica. Rosario: Prohistoria.

" Marengo Hecker, M. E. (2018). Los servicios de inteligencia de la Política de la provincia de Buenos Aires y la construcción del "sujeto comunista" (1955-1962). Tesis del Doctorado en Historia, UNLP.

"Nassif, S. (2016) Tucumán en llamas. El cierre de ingenios y la lucha obrera contra la dictadura (1966-1973). Buenos Aires: Humanitas.

"Nazar, M. (2008). El problema de la verdad histórica. Elementos para la configuración del concepto de trabajador construido desde el Estado durante el primer peronismo (19461955). Tesis de la licenciatura en Historia, Buenos Aires, Universidad de Buenos Aires.

"Negretto, G. (1995). El problema de la emergencia en el sistema constitucional. Buenos Aires: Depalma.

" Nemec, D. (2019) Pueblos de la guerra. Pueblos de la paz. Tucumán: EDUNT.

Perdía, R. y H. Silva (2017). Trienio en rojo y negro. Buenos Aires: Planeta.

" Pereyra, S.; G. Vommaro y G. Pérez (eds.) (2013). La grieta. Política, economía y cultura después de 2001. Buenos Aires: Biblos. 
" Pérez, P. (2016). Archivos del silencio. Estado, indígenas y violencia en Patagonia central, 1878-1941. Buenos Aires: Prometeo.

„Pérez Álvarez, G. y Gatica, M. (2020). Modalidades represivas contra los trabajadores chilenos en la Patagonia argentina: el caso de los obreros expulsados de Chubut. Revista Páginas, Año 12, v. 28, pp. 1-24.

" Piliponsky, E. (2014). La gran huelga azucarera de 1949 y la autonomía sindical. El consenso acerca de la represión y la coerción. Historia del movimiento obrero y la izquierda. 5.

"Pontoriero, E. (2012). De la conmoción interior a la guerra revolucionaria: legislación de defensa, pensamiento militar y caracterización de la amenaza a la seguridad interna en la Argentina (1958-1970), Tesis de Licenciatura, Departamento de Historia, Universidad Nacional de Tres de Febrero.

"Pontoriero, E. (2015) Estado de excepción y contrainsurgencia: El Plan CONINTES y la militarización de la seguridad interna en la Argentina (1958-1962), Contenciosa, Año 4, № 3.

" Pontoriero, E. (2017). La seguridad interna como 'teatro de guerra': estado de excepción y contrainsurgencia en Argentina (1955-1976). Tesis de Doctorado, Instituto de Altos Estudios Sociales, Universidad Nacional de San Martín, Buenos Aires.

" Potash, R. (1969). The Army and Politics in Argentina. Stanford: Stanford University Press.

" Potash, R. (1980). The Army and Politics in Argentina, 1945-1962, Perón to Frondizi. Stanford: Leland Stanford Junior University.

" Potash, R. (1994). The Army and Politics in Argentina, 1962-1973. Stanford: Leland Stanford Junior University.

" Rep, M. (2010). 200 años de peronismo. Biografía no autorizada de la Argentina. Buenos Aires: Planeta.

" Rico, Á. (comp.) (2006). ¿Cómo nos domina la clase gobernante?. Montevideo: Trilce.

" Rodríguez Agüero, L. (2013). Ciclo de protestas, experiencias organizativas y represión paraestatal: Mendoza, 1972-1976. Tesis de posgrado. Universidad Nacional de La Plata. Facultad de Humanidades y Ciencias de la Educación.

" Rodríguez Molas, R. (1984). Historia de la tortura y el orden represivo en Argentina. Buenos Aires: EUDEBA.

" Rouquié, A. (1978). Pouvoir militaire et société politique en République Argentine, 2 tomos. Paris: Presses de la Fondation Nationale de Sciences Po.

"Sain, M. F. (2008). El Leviatán azul: policía y política en la Argentina. Buenos Aires: Siglo XXI Ediciones.

"Schnyder, C. (2013). Política y violencia. Santiago del Estero 1995-2004. Santiago del Estero, EDUNSE.

"Silva, H. (2011). Días rojos, verano negro. Buenos Aires: Libros Anarres.

"Slatman, M. (2016). El Cono Sur de las dictaduras, los eslabonamientos nacionales en el interior de la Operación Cóndor y las particularidades del caso argentino. En Águila, G., S. Garaño y P. Scatizza (eds.), Violencias de Estado. Formas y dinámicas represivas en la historia reciente argentina: nuevos abordajes a 40 años del Golpe de Estado. Buenos Aires: UNLP, pp. 451-474.

"Solans, P. (2013). Crímenes en sangre: la verdad sobre la masacre de Napalpí, Buenos Aires: Sudestada de Bolsillo.

"Suriano, J. (2001). Anarquistas: cultura y política libertaria en Buenos Aires, 1890-1910. 
Buenos Aires: Manantial.

"Tiscornia, S. (2016). La violencia institucional como tema de trabajo e investigación. Espacios de Crítica y Producción, 53, pp. 25-32.

"Tortti, M. C. (2004). Protesta social y nueva izquierda en la Argentina del Gran Acuerdo Nacional. En: Pucciarelli A. (ed.), La primacía de la política. Lanusse, Perón y la nueva izquierda en tiempos del GAN. Buenos Aires: Eudeba, pp. 205-230.

" Trinchero, H. (2000). "Los Dominios del Demonio". Civilización y Barbarie en las fronteras de la Nación. El Chaco Central. Buenos Aires: Eudeba.

"Verbitsky, H. y Bohoslavsky, J. P., comp. (2013) Cuentas pendientes. Los cómplices económicos de la dictadura. Buenos Aires Siglo Veintiuno.

"Vidal, M. (2006). Napalpí. La herida abierta. Resistencia: Librería de la Paz.

"Ziulu, A. (2000). Estado de sitio. ¿Emergencia necesaria o autoritarismo encubierto? Buenos Aires: Depalma. 